\title{
Prospective study of dietary energy density and weight gain in a Japanese adult population
}

\author{
K. M. Sasaki ${ }^{1}$, K. Wada ${ }^{2}$, J. L. L. Zeredo ${ }^{3,4}$ and C. Nagata ${ }^{2 *}$ \\ ${ }^{1}$ Brazilian Ministry of Health, Oswaldo Cruz Foundation (FIOCRUZ), 70910-900 Brasilia, Brazil \\ ${ }^{2}$ Department of Epidemiology \& Preventive Medicine, Gifu University Graduate School of Medicine, Gifu 501-1194, Japan \\ ${ }^{3}$ Graduate Program in Health Science and Technology, University of Brasilia, 72220-275 Brasilia, Brazil \\ ${ }^{4}$ Department of Hard Tissue Engineering, Tokyo Medical and Dental University, Tokyo 113-8510, Japan
}

(Submitted 30 August 2016 - Final revision received 5 February 2017 - Accepted 7 February 2017 - First published online 11 April 2017)

\section{Abstract}

High dietary energy density (ED) has been associated with weight gain. However, little is known about the long-term effects of ED on weight changes among free-living subjects, particularly in Japanese and other Asian populations. In this study, we assessed dietary habits and weight changes in participants ( 5778 males and 7440 females, 35-69 years old) of the Takayama study. ED was estimated using a validated FFQ at baseline only. Information on body weight (BW) was obtained by self-administered questionnaires at baseline and follow-up. Mean BW difference in 9.8 years was 17 (SE 4221) g for men and -210 (sE 3889) g for women. In men, ED was positively associated with BW at follow-up after controlling for age, BW, height, physical activity score, alcohol consumption, energy intake, years of education at the baseline and change of smoking status during the follow-up. On average, men in the highest quartile of ED (>5.322 kJ/g (>1.272 kcal/g)) gained 138 (sE 111) g, whereas men in the lowest ED $(<1 \cdot 057)$ lost 22 (sE 111) g $\left(P_{\text {for trend }}=0 \cdot 01\right)$. The association between ED and BW gain was stronger in men with normal weight. In women, the association between ED and weight change was not statistically significant. In conclusion, contrary to some studies that report an association between ED and weight gain in the overweight only, our data suggest that high-ED diets may be associated with weight gain in the lean population as well, at least in male subjects.

\section{Key words: Energy density: Weight changes: Prospective studies: Diets: Obesity}

Worldwide, obesity and overweight are highly prevalent risk factors for a number of chronic conditions, including diabetes, CVD and cancer $^{(1)}$ Despite its lower incidence in Japan (as compared with other countries), obesity still raises publichealth concerns here, especially towards male adults, children and adolescents ${ }^{(2,3)}$. Therefore, there has been much interest in exploring possible determinants of weight gain. Among various factors suggested to play important roles in weight control, the energy density (ED) of foods has received considerable attention $^{(1,4-7)}$. ED is defined as the available dietary energy in a given unit of weight $(\mathrm{kJ} / \mathrm{g}(\mathrm{kcal} / \mathrm{g}))^{(6,7)}$. It has been reported that an increase in the ED of a diet, if not compensated by a reduction in the total amount of food consumed, would lead to a passive increase in energy intake, because people who maintain a constant body weight (BW) are used to eating a relatively constant weight of food ${ }^{(4,8)}$.

Most controlled trials report a relationship between dietary ED and weight gain in the overweight and/or obese population, with manipulation of the ED among groups ${ }^{(9-15)}$; however, these interventions were of relatively short duration. Observational studies, which can reflect the influence of the usual diet over a longer period of time, would corroborate or supplement the results of interventional studies. Nevertheless, observational studies among free-living people have been few and inconclusive $^{(16-21)}$. In addition, available studies have been mostly based on data from the USA and Europe. Therefore, data are needed regarding non-Western populations about the relationships between ED and BW changes. The objective of this study was to examine the relationships between dietary ED and weight gain during about 10 years of follow-up in a cohort of the Japanese adult population.

\section{Methods}

\section{Study population}

Subjects for this study were cohort members from the Takayama Study, a population-based cohort study conducted in Takayama City, Gifu, Japan. In brief, the Takayama Study is an ongoing prospective cohort study that aims to investigate associations between lifestyle factors and chronic diseases. In 1992, baseline data were collected from 31152 persons

Abbreviations: BW, body weight; ED, energy density.

* Corresponding author: Dr C. Nagata, fax +81 58230 6413, email chisato@gifu-u.ac.jp 
aged over 35 years, which yielded a participation rate of $85.3 \%$ of a total of 36990 residents invited. A detailed description of the study design and methods used can be found elsewhere ${ }^{(22)}$.

\section{Dietary and non-dietary measurements}

At baseline, diet, lifestyle and health-related variables were collected using a self-administered questionnaire. These included questions on demographic characteristics (age, BW, height, sex), education level, smoking, diet, physical activity and medical and reproductive histories (menopausal status and use of hormone replacement therapy). Diet, including alcoholic beverages, was assessed with a validated 169-item semi-quantitative FFQ. For each food item or dish, subjects were asked about consumption frequency and usual unit or portion size during the previous 1 year. Based on these data, daily intake of nutrients and food groups was calculated. ED was calculated for each subject by dividing daily energy intake ( $\mathrm{kJ}(\mathrm{kcal}))$ by the total weight of food consumed ( $\mathrm{g}$ ) based on food only (excluding all beverages). We chose this method for the calculation of ED because (1) it is reportedly the most commonly used and (2) individuals do not eat less food to compensate for energy added by beverages ${ }^{(23)}$. A detailed description of the FFQ, its reliability and validity ${ }^{(24)}$ and the method used for calculating nutrient intakes has been published previously ${ }^{(25)}$.

BMI was calculated as BW (kg) divided by the square of body height $\left(\mathrm{m}^{2}\right)$. Physical activity was assessed by asking the average hours per week spent performing various kinds of activities during the previous year. The time per week spent at each intensity of activity was multiplied by its corresponding energy expenditure requirements, expressed as a metabolic equivalents (MET), and summed up to yield a score (MET-h/week). The details including its validity are described elsewhere ${ }^{(26)}$.

\section{Follow-up survey}

In July 2002, we conducted a follow-up survey to assess BW in the population. The study subjects for the follow-up survey were restricted to those who were 70 years of age or younger at baseline ( $n$ 26546). Among these, between 1 September 1992 and 1 July 2002, 1505 participants were deceased, fifty-one participants were physically unable to complete the questionnaire and 2598 participants had moved. Of the remaining 22392 individuals to whom we sent the questionnaire, 14975 (66.9\%) (6674 men and 8301 women) responded. The questionnaire included questions on BW, smoking status, medical and reproductive histories. BMI did not differ between respondents and non-respondents, as described elsewhere ${ }^{(27)}$. Age-adjusted means of ED did not differ between respondents and non-respondents in men $(4.85 v .4 .85 \mathrm{~kJ} / \mathrm{g}(1.16 v$. $1 \cdot 16 \mathrm{kcal} / \mathrm{g})$ ). Female respondents were more likely to have had lower $\mathrm{ED}$ than non-respondents $(4.69 v .4 .73 \mathrm{~kJ} / \mathrm{g}(1.12 v$. $1 \cdot 13 \mathrm{kcal} / \mathrm{g})$ ). Height was considered stable among the examined adult population; therefore, we chose to report the outcome variable as changes in $\mathrm{BW}(\mathrm{g})$, rather than changes in BMI. The outcome variable was defined as the difference in BW between baseline and follow-up.
For the present analysis, subjects who reported having cancer (sixty-two men and 212 women), diabetes (372 men and 169 women), ischaemic heart disease (229 men and 236 women) and stroke (fifty men and twenty women) at the baseline were excluded, because these conditions usually require dietary restrictions. In addition, 407 subjects ( 183 men and 224 women) were excluded because of incomplete responses to the questions concerning height and BW. The response rate after the above-mentioned exclusions was $66.7 \%$. Hence, the analytic population at baseline consisted of 13218 subjects (5778 men and 7440 women). This study was conducted according to the guidelines laid down in the Declaration of Helsinki, and all procedures involving human subjects were approved by the ethical board of Gifu University Graduate School of Medicine. Written informed consent was obtained from all subjects.

\section{Statistical analysis}

The association between dietary ED and change in BW was investigated using multiple regression analyses (PROC GLM) and other SAS statistical procedures. The means of weight change according to quartile (Q) of ED were calculated. All analyses were stratified by sex. Covariates included in the models were the following: age, BW, height, physical activity score, alcohol consumption $(\mathrm{ml} / \mathrm{d})$, energy intake $(\mathrm{kcal} / \mathrm{d})$ and years of education ( $<11$ years, $12-14$ years $>15$ years) and menopausal status (premenopausal, postmenopausal and women only) at baseline and change in smoking status during the follow-up (never to never, never to current/former, former to former, current to former, former to current, current to current and unknown). These variables are known or suggested potential confounders from previous studies ${ }^{(28,29)}$. Furthermore, potential confounding effects of dietary intakes of total fat $(\mathrm{g} / \mathrm{d})$, vegetables $(\mathrm{g} / \mathrm{d})$, glycaemic load and coffee (cups/d) were included in the model. The glycaemic load is the calculated product of the carbohydrate content and glycaemic index, as described previously ${ }^{(30)}$ Tests for linear trend across quartiles of dietary ED were performed by treating the median of ED for each quartile as continuous variables.

\section{Results}

Tables 1 and 2 describe the characteristics of the population according to quartiles of dietary ED in men and women at baseline (1992). At the baseline, differences in BW, BMI and physical activity score among those with ED in Q1 relative to Q4 were not statistically significant in either male or female populations $(P>0.05)$. ED, age, alcohol and caffeine intake and glycaemic load were higher and vegetable intake was lower among those with ED in Q4 relative to Q1 in both men and women $(P=<0.05)$. Interestingly, total energy and fat intakes were higher among those with $\mathrm{ED}$ in $\mathrm{Q} 4$ relative to $\mathrm{Q} 1$ in women, but not in men.

The prospective variation of weight gain associated with dietary ED in men and women is shown in Tables 3 and 4 , respectively. The mean BW changes in 9 years and 10 months were 17 (sE 4221) and -210 (sE 3889) g for men and 
Table 1. Characteristics according to quartiles $(Q)$ of dietary energy density (ED) in the male population at baseline (1992) (Mean values and standard deviations)

\begin{tabular}{|c|c|c|c|c|c|c|c|c|c|}
\hline & \multicolumn{2}{|c|}{ Q1 } & \multicolumn{2}{|c|}{ Q2 } & \multicolumn{2}{|c|}{ Q3 } & \multicolumn{2}{|c|}{ Q4 } & \multirow[b]{2}{*}{$P^{*}$} \\
\hline & Mean & SD & Mean & SD & Mean & SD & Mean & SD & \\
\hline Dietary ED (kJ/g) & 4.02 & 0.29 & 4.64 & 0.12 & $5 \cdot 10$ & 0.12 & 5.69 & 0.33 & $<0.0001$ \\
\hline $\begin{array}{l}\text { Dietary ED }(\mathrm{kcal} / \mathrm{g}) \dagger \\
n\end{array}$ & $\begin{array}{r}0.96 \\
1\end{array}$ & 0.07 & 1444 & 0.03 & $\begin{array}{r}1.22 \\
1\end{array}$ & 0.03 & $\begin{array}{r}1.36 \\
1\end{array}$ & 1445 & $<0.0001$ \\
\hline Age (years) & 54.0 & 8.5 & $52 \cdot 8$ & 8.9 & $51 \cdot 1$ & 8.9 & 49.0 & 8.8 & $<0.0001$ \\
\hline BW at baseline $(\mathrm{kg})$ & 61.5 & 8.6 & 61.6 & 8.4 & 61.8 & 8.8 & $62 \cdot 0$ & $8 \cdot 7$ & 0.12 \\
\hline Height $(\mathrm{cm})$ & $164 \cdot 6$ & $6 \cdot 4$ & $164 \cdot 8$ & $6 \cdot 1$ & $165 \cdot 3$ & $6 \cdot 2$ & $165 \cdot 8$ & $6 \cdot 2$ & $<0.0001$ \\
\hline BMI at baseline $\left(\mathrm{kg} / \mathrm{m}^{2}\right)$ & $22 \cdot 7$ & $2 \cdot 7$ & 22.7 & 2.5 & $22 \cdot 6$ & $2 \cdot 6$ & 22.5 & 2.6 & 0.09 \\
\hline Physical activity score (MET-h/week) & 27.5 & $39 \cdot 7$ & 30.0 & 43.0 & 29.6 & $43 \cdot 1$ & 28.0 & $42 \cdot 2$ & 0.75 \\
\hline Alcohol intake (ml/d) & 50.8 & 43.4 & $46 \cdot 6$ & 41.6 & 41.2 & 39.5 & $36 \cdot 8$ & $36 \cdot 0$ & $<0.0001$ \\
\hline Total energy intake $(\mathrm{kJ} / \mathrm{d})$ & 11149.5 & 3732.1 & 11339.0 & 3674.8 & 11171.2 & 3211.6 & $11166 \cdot 2$ & $3315 \cdot 8$ & 0.90 \\
\hline Total energy intake $(\mathrm{kcal} / \mathrm{d})$ & 2664.8 & 892.0 & $2710 \cdot 1$ & 878.3 & $2670 \cdot 0$ & 767.6 & 2668.8 & 792.5 & 0.90 \\
\hline Years of education (\%) & \multirow{2}{*}{\multicolumn{2}{|c|}{$55 \cdot 2$}} & \multirow{2}{*}{\multicolumn{2}{|c|}{53.5}} & \multirow{2}{*}{\multicolumn{2}{|c|}{49.9}} & \multirow{2}{*}{\multicolumn{2}{|c|}{$46 \cdot 0$}} & $<0.001$ \\
\hline$<12$ & & & & & & & & & \\
\hline $12-14$ & \multicolumn{2}{|c|}{$33 \cdot 4$} & \multicolumn{2}{|c|}{34.4} & \multicolumn{2}{|c|}{$37 \cdot 7$} & \multicolumn{2}{|c|}{$40 \cdot 8$} & \\
\hline$\geq 15$ & \multicolumn{2}{|c|}{11.4} & \multicolumn{2}{|c|}{$12 \cdot 1$} & \multicolumn{2}{|c|}{12.5} & \multicolumn{2}{|c|}{$13 \cdot 3$} & \\
\hline Smoking status (\%) & & & & & & & & & 0.0006 \\
\hline Never to never & \multicolumn{2}{|c|}{$18 \cdot 0$} & \multicolumn{2}{|c|}{$16 \cdot 3$} & \multicolumn{2}{|c|}{$15 \cdot 8$} & \multicolumn{2}{|c|}{$16 \cdot 0$} & \\
\hline Never to current/former & \multicolumn{2}{|c|}{0.0} & \multicolumn{2}{|c|}{0.1} & \multicolumn{2}{|c|}{$0 \cdot 1$} & \multicolumn{2}{|c|}{0.1} & \\
\hline Current to current & \multicolumn{2}{|c|}{33.5} & \multicolumn{2}{|c|}{$36 \cdot 2$} & & & & & \\
\hline Current to former & & & & & & & & & \\
\hline Former to current & & & & & & & & & \\
\hline Former to former & & & & & & & & & \\
\hline Total fat intake $(\mathrm{g} / \mathrm{d})$ & 61.8 & 27.9 & $62 \cdot 4$ & $28 \cdot 3$ & 60.3 & $26 \cdot 6$ & 60.5 & 28.4 & 0.22 \\
\hline Vegetables intake $(\mathrm{g} / \mathrm{d})$ & 523.0 & $346 \cdot 3$ & 394.4 & $219 \cdot 2$ & $315 \cdot 8$ & $152 \cdot 9$ & 241.7 & $127 \cdot 8$ & $<0.0001$ \\
\hline Glycaemic load & $201 \cdot 6$ & 71.6 & $226 \cdot 9$ & $70 \cdot 1$ & $240 \cdot 0$ & 62.5 & $252 \cdot 1$ & $67 \cdot 2$ & $<0.0001$ \\
\hline Coffee intake (cups/d) & 0.7 & 0.9 & 0.8 & 0.9 & 0.9 & 1.0 & $1 \cdot 1$ & 1.0 & $<0.0001$ \\
\hline
\end{tabular}

BW, body weight; MET, metabolic equivalents.

* $P$ values for difference of means or $X^{2}$ test for Q1 v. Q4.

† Dietary ED medians for Q1, Q2, Q3 and Q4 were 0.98, 1.11, 1.22 and 1.34, respectively.

women, respectively. The present data are in accordance with previous epidemiological studies, which report a low incidence of obesity and mostly stable (but also decreasing) BMI in the Japanese population $^{(30,31)}$. Our FFQ was designed to measure an individual's relative intake of nutrients rather than absolute values. Some of the values for dietary nutrients and food groups may have been overestimated by our questionnaire. The mean values estimated from the FFQ were generally higher than those estimated from twelve daily diet records.

Table 3 shows that male participants with greater dietary ED at baseline experienced significantly greater weight gain ( $P_{\text {for trend }}=0.01$ ), after controlling for the covariates. Even when total energy was not included as a covariate, the result was not altered: the weight change for $4 \mathrm{~kJ} / \mathrm{g}(1 \mathrm{kcal} / \mathrm{g})$ ED was 1.09 (sE 0.43$) \mathrm{kg}\left(P_{\text {for trend }}=0.01\right)$. Besides age, weight, height and alcohol intake at baseline and smoking cessation at follow-up were found to be significant confounders. Additional adjustment for dietary intake of total fat, vegetables, glycaemic load and coffee somewhat strengthened the association between ED and weight change in all men. The mean weight differences were -295 (SE 131), -334 (SE 110), -68 (SE 112) and 196 (sE 124) g from the lowest to the highest quartiles, respectively. The weight change for $4 \mathrm{~kJ} / \mathrm{g}$ ( $1 \mathrm{kcal} / \mathrm{g})$ ED was 1.51 (SE 0.55$) \mathrm{kg} \quad\left(P_{\text {for }}\right.$ trend $\left.=0.006\right)$ in the entire group. However, these dietary factors, as well as the major macronutrients proteins and carbohydrates, did not show statistically significant relationships with weight change. A somewhat stronger association between ED and weight gain was observed in individuals who ingested an above-median amount of carbohydrates (the weight changes for $4 \mathrm{~kJ} / \mathrm{g}$ ( $1 \mathrm{kcal} / \mathrm{g}$ ) ED were 1.41 (SE 0.63 ) and 0.77 (SE 0.59) kg for high- and low-carbohydrate intake, respectively). However, the interaction term was not statistically significant $(P=0 \cdot 65)$. Likewise, fat and protein intake were not modifiers of the relationship between ED and weight change. The correlation between dietary fibre and vegetable intake was high ( $r$ 0.91) and adjustment for dietary fibre instead of vegetables did not alter the results. Physical activity was assessed at follow-up. Additional adjustment for physical activity at follow-up or use of the mean of physical activity scores at baseline and follow-up did not alter the results.

Exclusion of $953(16.5 \%)$ men with $\mathrm{BMI} \geq 25 \mathrm{~kg} / \mathrm{m}^{2}$ somewhat strengthened the association between ED and weight change; the weight change for $4 \mathrm{~kJ} / \mathrm{g}(1 \mathrm{kcal} / \mathrm{g})$ ED was $1.69 \mathrm{~kg}$ $\left(P_{\text {for }}\right.$ trend $=0.003$ ). Exclusion of men with $\mathrm{BMI} \geq 23 \mathrm{~kg} / \mathrm{m}^{2}$ instead of $\mathrm{BMI} \geq 25 \mathrm{~kg} / \mathrm{m}^{2}$ did not alter the results substantially: the weight change for $4 \mathrm{~kJ} / \mathrm{g}$ ( $1 \mathrm{kcal} / \mathrm{g}$ ) ED was 1.88 (sE 0.70$) \mathrm{kg}$ ( $P_{\text {for trend }}=0 \cdot 007$ ).

There was no significant association between ED and weight change in either the total women population or in normalweight women only (Table 4). Additional adjustment for dietary factors or physical activity at follow-up did not alter the results.

\section{Discussion}

In the present study, we observed a significant association between high-ED diet and BW gain among Japanese males, but not females. So far, to our knowledge, four studies have 
Table 2. Characteristics according to quartiles (Q) of dietary energy density (ED) in the female population at baseline (1992) (Mean values and standard deviations)

\begin{tabular}{|c|c|c|c|c|c|c|c|c|c|}
\hline & \multicolumn{2}{|c|}{ Q1 } & \multicolumn{2}{|c|}{ Q2 } & \multicolumn{2}{|c|}{ Q3 } & \multicolumn{2}{|c|}{ Q4 } & \multirow[b]{2}{*}{$P^{*}$} \\
\hline & Mean & SD & Mean & SD & Mean & SD & Mean & SD & \\
\hline Dietary ED (kJ/g) & 3.89 & 0.29 & 4.47 & 0.12 & 4.89 & 0.12 & 5.52 & 0.33 & $<0.0001$ \\
\hline Dietary ED $(\mathrm{kcal} / \mathrm{g}) \dagger$ & 0.93 & 0.07 & 1.07 & 0.03 & 1.17 & 0.03 & 1.32 & 0.08 & $<0.0001$ \\
\hline$n$ & \multicolumn{2}{|c|}{1880} & \multicolumn{2}{|c|}{1880} & \multicolumn{2}{|c|}{1880} & \multicolumn{2}{|c|}{1880} & \\
\hline Age (years) & 54.1 & 8.7 & $52 \cdot 0$ & $9 \cdot 1$ & 50.7 & 9.0 & 48.6 & $8 \cdot 7$ & $<0.0001$ \\
\hline BW at baseline $(\mathrm{kg})$ & $51 \cdot 7$ & $7 \cdot 0$ & $52 \cdot 0$ & $6 \cdot 9$ & 51.9 & 6.9 & $51 \cdot 8$ & $7 \cdot 1$ & 0.63 \\
\hline Height $(\mathrm{cm})$ & $152 \cdot 3$ & 5.4 & $153 \cdot 1$ & 5.4 & $153 \cdot 2$ & 5.5 & $153 \cdot 8$ & 5.4 & $<0.0001$ \\
\hline BMI at baseline $\left(\mathrm{kg} / \mathrm{m}^{2}\right)$ & $22 \cdot 3$ & $2 \cdot 8$ & $22 \cdot 2$ & $2 \cdot 2$ & $22 \cdot 1$ & 2.6 & 21.9 & $2 \cdot 7$ & $<0.0001$ \\
\hline Physical activity score (MET-h/week) & $22 \cdot 1$ & $32 \cdot 3$ & $21 \cdot 2$ & $30 \cdot 0$ & $22 \cdot 6$ & $9 \cdot 0$ & 21.0 & $30 \cdot 4$ & 0.28 \\
\hline Alcohol intake (ml/d) & 8.4 & $18 \cdot 1$ & 7.0 & $14 \cdot 0$ & $7 \cdot 7$ & 14.9 & 7.4 & $14 \cdot 3$ & 0.05 \\
\hline Total energy intake $(\mathrm{kJ} / \mathrm{d})$ & $8946 \cdot 6$ & 3171.9 & 9033.7 & 3074.4 & $9284 \cdot 2$ & $3129 \cdot 2$ & 9430.3 & $3209 \cdot 1$ & 0.90 \\
\hline Total energy intake $(\mathrm{kcal} / \mathrm{d})$ & $2138 \cdot 3$ & $758 \cdot 1$ & $2159 \cdot 1$ & 734.8 & $2219 \cdot 0$ & 747.9 & 2253.9 & $767 \cdot 0$ & 0.90 \\
\hline Years of education (\%) & & & & & & & & & $<0.0001$ \\
\hline$<12$ & \multicolumn{2}{|c|}{$55 \cdot 2$} & \multicolumn{2}{|c|}{53.5} & \multicolumn{2}{|c|}{49.9} & \multicolumn{2}{|c|}{45.9} & \\
\hline $12-14$ & \multicolumn{2}{|c|}{$33 \cdot 4$} & \multicolumn{2}{|c|}{34.4} & \multicolumn{2}{|c|}{$37 \cdot 7$} & \multicolumn{2}{|c|}{$40 \cdot 8$} & \\
\hline$\geq 15$ & \multicolumn{2}{|c|}{11.4} & \multicolumn{2}{|c|}{$12 \cdot 1$} & \multicolumn{2}{|c|}{$12 \cdot 4$} & \multicolumn{2}{|c|}{$13 \cdot 3$} & \\
\hline Menopausal status (\%) & & & & & & & & & $<0.0001$ \\
\hline Premenopausal & \multicolumn{2}{|c|}{$17 \cdot 0$} & \multicolumn{2}{|c|}{22.5} & \multicolumn{2}{|c|}{27.5} & \multicolumn{2}{|c|}{33.0} & \\
\hline Postmenopausal & \multicolumn{2}{|c|}{$17 \cdot 6$} & \multicolumn{2}{|c|}{$15 \cdot 2$} & \multicolumn{2}{|c|}{$13 \cdot 0$} & \multicolumn{2}{|c|}{$10 \cdot 6$} & \\
\hline Smoking status (\%) & & & & & & & & & $<0.0001$ \\
\hline Never to never & & & & & & & & & \\
\hline Never to current/former & & & & & & & & & \\
\hline Current to current & & & & & & & & & \\
\hline Current to former & & & & & & & & & \\
\hline Former to current & & & & & & & & & \\
\hline Former to former & & & & & & & & & \\
\hline Total fat intake $(\mathrm{g} / \mathrm{d})$ & 56.6 & $25 \cdot 0$ & $57 \cdot 8$ & $25 \cdot 3$ & $58 \cdot 6$ & $26 \cdot 3$ & 58.4 & 28.5 & 0.047 \\
\hline Vegetables intake $(\mathrm{g} / \mathrm{d})$ & 575.5 & $340 \cdot 6$ & 414.4 & $214 \cdot 6$ & $351 \cdot 7$ & 183.9 & $266 \cdot 1$ & $140 \cdot 2$ & $<0.0001$ \\
\hline Glycaemic load & 173.3 & 57.7 & $187 \cdot 7$ & 61.9 & 0.7 & 0.9 & $218 \cdot 0$ & $67 \cdot 0$ & $<0.0001$ \\
\hline Coffee intake (cups/d) & 0.6 & 0.8 & 0.7 & 0.9 & 0.7 & 0.9 & 0.9 & 1.0 & $<0.0001$ \\
\hline
\end{tabular}

BW, body weight; MET, metabolic equivalents.

* $P$ values for difference of means or chi-square test for Q1 v. Q4.

† Dietary ED medians for Q1, Q2, Q3 and Q4 were 0.95, 1.07, 1.17 and 1.30, respectively.

reported an association between ED and subsequent weight change in free-living populations ${ }^{(16,18-20)}$. None of these studies included the Japanese or other Asians. Two of them observed a significantly positive association in overweight $\left(\geq 25 \mathrm{~kg} / \mathrm{m}^{2}\right)$ subjects but not in normal-weight subjects ${ }^{(16,18)}$. In the former study, of 1762 Danish men and women, a significantly positive association was observed in obese women only, but the calculation of dietary ED included beverages and water, which differed from other studies ${ }^{(16)}$. In the latter study, of 2707 French men and women, the mean weight gain over 6 years was $2 \cdot 41 v$. $1.45 \mathrm{~kg}$ for the highest as compared with the lowest tertile of ED (median ED $1.58 v .1 \cdot 16$ ), respectively, in overweight men and women $^{(18)}$. Another study, of 89432 subjects from five European countries, also reported that ED was not significantly associated with weight change in subjects with baseline BMI $<25 \mathrm{~kg} / \mathrm{m}^{2}$ (change of weight was $0.029 \mathrm{~kg} /$ year for $4 \mathrm{~kJ} / \mathrm{g}(1 \mathrm{kcal} / \mathrm{g}) \mathrm{ED}$ ), but the association was non-significantly inverse in those with BMI $\geq 25 \mathrm{~kg} / \mathrm{m}^{2(19)}$. The remaining study, of 192 non-Hispanic White women in the USA, observed a greater positive association in the entire group: the mean weight gain over 6 years were 6.4 v. $2.5 \mathrm{~kg}$ for high $(\geq 7.74 \mathrm{~kJ} / \mathrm{g}(\geq 1.85 \mathrm{kcal} / \mathrm{g}))$ as compared with low ED $(\leq 6.3 \mathrm{~kJ} / \mathrm{g}(\leq 1.5 \mathrm{kcal} / \mathrm{g}))$ diet, but the association did not vary by BMI classification ${ }^{(20)}$.

The present study demonstrated a significantly positive trend for the association between ED and weight change in a
Japanese male population, which is generally lean. Furthermore, this association was strengthened by restricting the population to normal-weight subjects only. The fact that dietary ED can be related to weight gain even in a lean population raises further concerns about the risks for overweight and obesity. We observed that total energy intake at baseline was unrelated to weight gain. We hypothesise that a high-ED diet may cause an increase in energy intake, which, in turn, leads to weight gain. Unfortunately, however, we could not evaluate the change in energy intake as well as ED after the baseline.

There has been a suggestion that normal-weight subjects are more physically active and therefore likely to be able to manage energy-dense diets more easily than overweight subjects. However, in our study, physical activity at the baseline, as well as at follow-up, was included as covariates. Although our results did not support that ED was unrelated to weight change in normal-weight men, there is a possibility that ethnicity rather than body size may modify the association between ED and weight change ${ }^{(32)}$.

We failed to observe a positive association between ED and weight change in women. The mechanism linking higher ED and a large gain in weight was speculated through an increase in total energy intake. In women, high-ED diet at baseline could not be linked to high-energy intake at follow-up because concern about weight gain may have influenced their diet. 
Table 3. Weight change in the male population by categories of dietary energy density (ED) (Mean values with their standard errors)

\begin{tabular}{|c|c|c|c|c|c|c|c|c|c|c|c|}
\hline & \multicolumn{8}{|c|}{ ED quartiles } & & & \\
\hline & \multicolumn{2}{|c|}{ Q1 } & \multicolumn{2}{|c|}{ Q2 } & \multicolumn{2}{|c|}{ Q3 } & \multicolumn{2}{|c|}{ Q4 } & \multicolumn{2}{|c|}{ Continuous (kg/1ED) } & \multirow[b]{2}{*}{$P_{\text {for trend }}{ }^{*}$} \\
\hline & Mean & SE & Mean & SE & Mean & SE & Mean & SE & Mean & SE & \\
\hline ED $(\mathrm{kJ} / \mathrm{g})-$ median & \multicolumn{2}{|c|}{$4 \cdot 10$} & \multicolumn{2}{|c|}{$4 \cdot 64$} & \multicolumn{2}{|c|}{$5 \cdot 10$} & \multicolumn{2}{|c|}{$5 \cdot 60$} & & & \\
\hline ED $(\mathrm{kcal} / \mathrm{g})$ - median & \multicolumn{2}{|c|}{0.98} & \multicolumn{2}{|c|}{$1 \cdot 11$} & \multicolumn{2}{|c|}{$1 \cdot 22$} & \multicolumn{2}{|c|}{1.34} & & & \\
\hline$\Delta \mathrm{ED}(\mathrm{kJ} / \mathrm{g})$ & \multicolumn{2}{|c|}{$<4.422$} & \multicolumn{2}{|c|}{4.422 to $<4.866$} & \multicolumn{2}{|c|}{4.866 to $<5.322$} & \multicolumn{2}{|c|}{$\geq 5.322$} & & & \\
\hline$\Delta \mathrm{ED}(\mathrm{kcal} / \mathrm{g})$ & \multicolumn{2}{|c|}{$<1.057$} & \multicolumn{2}{|c|}{1.057 to $<1.163$} & \multicolumn{2}{|c|}{1.163 to $<1.272$} & \multicolumn{2}{|c|}{$\geq 1 \cdot 272$} & & & \\
\hline All & \multicolumn{2}{|c|}{ n 1445} & \multicolumn{2}{|c|}{$n 1444$} & \multicolumn{2}{|c|}{$n 1444$} & \multicolumn{2}{|c|}{ n 1445} & & & \\
\hline Change in BW $(\mathrm{g}) \dagger$ & -22 & 111 & -324 & 111 & -95 & 111 & 138 & 111 & 1.07 & 0.43 & 0.01 \\
\hline Change in BW $(\mathrm{g}) \ddagger$ & -295 & 131 & -334 & 110 & -68 & 112 & 196 & 124 & 1.51 & 0.55 & 0.006 \\
\hline In subjects with $\mathrm{BMl}<25 \mathrm{~kg} / \mathrm{m}^{2}$ & \multicolumn{2}{|c|}{$n 1205$} & \multicolumn{2}{|c|}{$n 1206$} & \multicolumn{2}{|c|}{$n 1205$} & \multicolumn{2}{|c|}{$n 1209$} & & & \\
\hline Change in BW $(\mathrm{g}) \dagger$ & 56 & 115 & -77 & 114 & 235 & 114 & 468 & 115 & $1 \cdot 28$ & 0.44 & 0.004 \\
\hline Change in BW $(\mathrm{g}) \ddagger$ & -13 & 137 & -86 & 114 & 259 & 117 & 521 & 129 & 1.69 & 0.57 & 0.003 \\
\hline
\end{tabular}

$\mathrm{Q}$, quartile; BW, body weight.

* $P$ linear trend across quartiles.

$\dagger$ Adjusted for age, BW, height, physical activity score, alcohol consumption, energy intake, years of education and change of smoking status.

¥ Additional adjustment for dietary intake of total fat, vegetables intake, glycaemic load and coffee intake.

Table 4. Weight change in the female population by categories of dietary energy density (ED)

(Mean values with their standard errors)

\begin{tabular}{|c|c|c|c|c|c|c|c|c|c|c|}
\hline & \multicolumn{7}{|c|}{ ED quartiles } & & & \\
\hline & Q1 & \multicolumn{2}{|c|}{ Q2 } & \multicolumn{2}{|c|}{ Q3 } & \multicolumn{2}{|c|}{ Q4 } & \multicolumn{2}{|c|}{ Continuous (kg/1ED) } & \multirow[b]{2}{*}{$P_{\text {for trend }}{ }^{*}$} \\
\hline & Mean & Mean & $\mathrm{SE}$ & Mean & SE & Mean & $\mathrm{SE}$ & Mean & SE & \\
\hline $\mathrm{ED}(\mathrm{kJ} / \mathrm{g})-$ median & 3.97 & \multicolumn{2}{|c|}{4.48} & \multicolumn{2}{|c|}{4.89} & \multicolumn{2}{|c|}{5.44} & & & \\
\hline ED $(\mathrm{kcal} / \mathrm{g})$ - median & 0.95 & \multicolumn{2}{|c|}{1.07} & \multicolumn{2}{|c|}{$1 \cdot 17$} & \multicolumn{2}{|c|}{1.30} & & & \\
\hline$\Delta \mathrm{ED}(\mathrm{kJ} / \mathrm{g})$ & $<4.276$ & \multicolumn{2}{|c|}{4.276 to $<4.707$} & \multicolumn{2}{|c|}{4.707 to $<5.134$} & \multicolumn{2}{|c|}{$\geq 5 \cdot 134$} & & & \\
\hline$\Delta \mathrm{ED}(\mathrm{kcal} / \mathrm{g})$ & $<1.022$ & \multicolumn{2}{|c|}{1.022 to $<1.125$} & \multicolumn{2}{|c|}{1.125 to $<1.227$} & \multicolumn{2}{|c|}{$\geq 1 \cdot 227$} & & & \\
\hline All & $n 1860$ & \multicolumn{2}{|c|}{$n 1860$} & \multicolumn{2}{|c|}{$n 1860$} & \multicolumn{2}{|c|}{$n 1860$} & & & \\
\hline $\begin{array}{l}\text { Change in BW }(\mathrm{g}) \dagger \\
\text { In subjects with } \mathrm{BMI}<25 \mathrm{~kg} / \mathrm{m}^{2}\end{array}$ & $\begin{array}{l}-274 \\
n 1582\end{array}$ & $\begin{array}{r}-236 \\
n\end{array}$ & 88 & $\begin{array}{r}-249 \\
n\end{array}$ & 88 & $\begin{array}{r}-273 \\
n 1\end{array}$ & $4^{89}$ & 0.008 & 0.35 & 0.98 \\
\hline Change in BW $(\mathrm{g}) \dagger$ & 190 & -55 & 90 & -152 & 90 & -154 & 91 & -0.48 & 0.36 & $0 \cdot 19$ \\
\hline
\end{tabular}

Q, quartile; BW, body weight.

* $P$ linear trend across quartiles.

† Adjusted for age, BW, height, physical activity score, alcohol consumption, energy intake, years of education, menopausal status and change of smoking status.

However, a study to determine the relationship between ED and subsequent energy intake would have to measure changes in diet repeatedly. Women are more concerned about weight and could under-report information about weight and high-ED food consumption ${ }^{(33)}$. Reports suggest that such underreporting is more common among female, obese and overweight subjects ${ }^{(34)}$, which may have led to the observed null association.

This study has the following known limitations. First, self-report of weight and diet may have had an influence on the results; nevertheless, our validity study showed that the correlation coefficients between self-reported and measured height and weight among a subsample was high; $r 0.85$ for height and $r 0.97$ for weight in men, and corresponding values were 0.93 and 0.97 , respectively, in women. In addition, our measurement of FFQ has been well validated for nutrients and food groups. Second, selective misclassification/mismeasurement of ED or weight may have occurred and this may be especially relevant to the results among women. However, considering that BMI and ED at baseline were similar between respondents and non-respondents, it is unlikely that men with high ED and high weight gain or men with low ED and low weight gain were selectively included into the study. Third, although much information was collected at follow-up, including changes in smoking status, for instance, we could not assess diet including ED as well as total energy intake at the follow-up. Fourth, the response rate was modest in this study and we could not obtain the BW status of subjects who had died or moved away during the follow-up period. On the other hand, strengths of the present study include its longitudinal design, a large number of subjects and a long follow-up period.

In conclusion, the present prospective study in Japanese men and women suggests that high-ED diets are positively associated with BW gain in the male population, including normalweight subjects, but not in the female population. Current dietary recommendations in Japan do not refer to ED. Further studies including prospective and interventional studies are needed to clarify the potential effects of ED on weight modification in the Japanese population. In addition, because studies on ED and weight gain are limited to Western 
populations, the present study ought to be repeated in other Asian populations.

\section{Acknowledgements}

The authors thank all the participants in the Takayama study.

This study was supported in part by Grants-in-Aid for Scientific Research from the Ministry of Education, Science, Sports, Culture and Technology of Japan and by a travel grant from the Federal District Research Foundation (Fundação de Amparo à Pesquisa do Distrito Federal FAP-DF) of Brazil to K. M. S.

K. M. S., K. W. and C. N. contributed to the study interpretation and to the writing of the manuscript. K. W. contributed to the statistical analysis. J. L. L. Z. provided input into the final draft of the manuscript. C. N. designed the study, conducted the statistical analysis and contributed to the hypothesis formulation.

The authors declare that there are no conflicts of interest.

\section{References}

1. World Health Organization (2016) Obesity and Overweight. Geneva: WHO

2. Matsuura B, Nunoi H, Miyake T, et al. (2013) Obesity and gastrointestinal liver disorders in Japan. J Gastroenterol Hepatol 28, Suppl. 4, 48-53.

3. Kubo T (2014) Common approach to childhood obesity in Japan. J Pediatr Endocrinol Metab 27, 581-592.

4. Poppitt SD \& Prentice AM (1996) Energy density and its role in the control of food intake: evidence from metabolic and community studies. Appetite 26, 153-174.

5. Westerterp-Plantenga MS (2004) Effects of energy density of daily food intake on long-term energy intake. Physiol Behav 81, 765-771.

6. Yao M \& Roberts SB (2001) Dietary energy density and weight regulation. Nutr Rev 59, 247-258.

7. Drewnowski A, Almiron-Roig E, Marmonier C, et al. (2004) Dietary energy density and body weight: is there a relationship? Nutr Rev 62, 403-413.

8. Bell EA, Castellanos VH, Pelkman CL, et al. (1998) Energy density of foods affects energy intake in normal-weight women. Am J Clin Nutr 67, 412-420.

9. Saris WH, Astrup A, Prentice AM, et al. (2000) Randomized controlled trial of changes in dietary carbohydrate/fat ratio and simple vs complex carbohydrates on body weight and blood lipids: the CARMEN study. The Carbohydrate Ratio Management in European National diets. Int J Obes Relat Metab Disord 24, 1310-1318.

10. Rolls BJ, Roe LS, Beach AM, et al. (2005) Provision of foods differing in energy density affects long-term weight loss. Obes Res 13, 1052-1060.

11. Ello-Martin JA, Roe LS, Ledikwe JH, et al. (2007) Dietary energy density in the treatment of obesity: a year-long trial comparing 2 weight-loss diets. Am J Clin Nutr 85, $1465-1477$.

12. Ledikwe JH, Rolls BJ, Smiciklas-Wright H, et al. (2007) Reductions in dietary energy density are associated with weight loss in overweight and obese participants in the PREMIER trial. Am J Clin Nutr 85, 1212-1221.

13. de Oliveira MC, Sichieri R \& Venturim Mozzer R (2008) A lowenergy-dense diet adding fruit reduces weight and energy intake in women. Appetite 51, 291-295.
14. Lowe MR, Tappe KA, Annunziato RA, et al. (2008) The effect of training in reduced energy density eating and food self-monitoring accuracy on weight loss maintenance. Obesity (Silver Spring) 16, 2016-2023.

15. Due A, Larsen TM, Mu H, et al. (2008) Comparison of 3 ad libitum diets for weight-loss maintenance, risk of cardiovascular disease, and diabetes: a 6-mo randomized, controlled trial. Am J Clin Nutr 88, 1232-1241.

16. Iqbal SI, Helge JW \& Heitmann BL (2006) Do energy density and dietary fiber influence subsequent 5-year weight changes in adult men and women? Obesity (Silver Spring) 14, 106-114.

17. Bes-Rastrollo M, van Dam RM, Martinez-Gonzalez MA, et al. (2008) Prospective study of dietary energy density and weight gain in women. Am J Clin Nutr 88, 769-777.

18. Vergnaud A-C, Estaquio C, Czernichow S, et al. (2009) Energy density and 6-year anthropometric changes in a middle-aged adult cohort. Br J Nutr 102, 302-309.

19. Du H, van der ADL, Ginder V, et al. (2009) Dietary energy density in relation to subsequent changes of weight and waist circumference in European men and women. PLOS ONE 4, e5339.

20. Savage JS, Marini M \& Birch LL (2008) Dietary energy density predicts women's weight change over 6 y. Am J Clin Nutr $\mathbf{8 8}$, 677-684

21. Romaguera D, Angquist L, Du H, et al. (2010) Dietary determinants of changes in waist circumference adjusted for body mass index - a proxy measure of visceral adiposity. PLOS ONE 5, e11588.

22. Shimizu H (1996) A basic report on Takayama study. Gifu University, Gifu.

23. Karl JP \& Roberts SB (2014) Energy density, energy intake, and body weight regulation in adults. Adv Nutr $\mathbf{5}$, 835-850.

24. Shimizu H (2002) A supplementary comment on 'Reliability and validity of a questionnaire for assessment of physical activity in epidemiological studies' published in Journal of Epidemiology, 1998. J Epidemiol 12, 54.

25. Shimizu H, Ohwaki A, Kurisu Y, et al. (1999) Validity and reproducibility of a quantitative food frequency questionnaire for a cohort study in Japan. Jpn J Clin Oncol 29, 38-44.

26. Suzuki I, Kawakami N \& Shimizu H (1998) Reliability and validity of a questionnaire for assessment of energy expenditure and physical activity in epidemiological studies. J Epidemiol 8, 152-159.

27. Nagata C, Nakamura K, Fujii K, et al. (2008) Smoking and risk of cedar pollinosis in Japanese men and women. Int Arch Allergy Immunol 147, 117-124.

28. Ledikwe JH, Blanck HM, Khan LK, et al. (2005) Dietary energy density determined by eight calculation methods in a nationally representative United States population. J Nutr 135, 273-278.

29. Aburto TC, Cantoral A, Hernández-Barrera L, et al. (2015) Usual dietary energy density distribution is positively associated with excess body weight in Mexican children. $J$ Nutr 145, 1524-1530.

30. Oba S, Nagata C, Nakamura K, et al. (2010) Dietary glycemic index, glycemic load, and intake of carbohydrate and rice in relation to risk of mortality from stroke and its subtypes in Japanese men and women. Metabolism 59, 1574-1582.

31. Murakami K, Sasaki S, Takahashi Y, et al. (2007) Dietary energy density is associated with body mass index and waist circumference, but not with other metabolic risk factors, in free-living young Japanese women. Nutrition $\mathbf{2 3}$, 798-806. 
32. Howarth NC, Murphy SP, Wilkens LR, et al. (2006) Dietary energy density is associated with overweight status among 5 ethnic groups in the multiethnic cohort study. J Nutr 136, 2243-2248.

33. Martí-Henneberg C, Capdevila F, Arija V, et al. (1999) Energy density of the diet, food volume and energy intake by age and sex in a healthy population. Eur J Clin Nutr $\mathbf{5 3}$, 421-428.

34. Macdiarmid J \& Blundell J (1998) Assessing dietary intake: who, what and why of under-reporting. Nutr Res Rev 11, 231-253. 